\title{
Induction Therapy with Bortezomib, Thalidomide and Dexamethasone (VTD) in Caucasian Patients with Multiple Myeloma: A Single Center Experience
}

Normann Steiner, Stephanie Riehl, David Nachbaur, Wolfgang Willenbacher, Gunther Gastl and Eberhard Gunsilius *

Department of Internal Medicine V (Hematology and Medical Oncology), Innsbruck Medical University, Anichstr. 35, A-6020 Innsbruck, Austria

*Corresponding author: Eberhard Gunsilius, Professor, Department of Internal Medicine V, Innsbruck Medical University, Anichstr. 35 , A-6020 Innsbruck, Austria, Tel: +43 5125040; Fax: +43 512504 25615; E-mail: eberhard.gunsilius@i-med.ac.at

Received date: Jun 10, 2015, Accepted date: Aug 14, 2015, Publication date: Aug 18, 2015

Copyright: ( 2015 Steiner N, et al. This is an open-access article distributed under the terms of the Creative Commons Attribution License, which permits unrestricted use, distribution, and reproduction in any medium, provided the original author and source are credited.

\begin{abstract}
Objective: In clinical trials, the combination of bortezomib, thalidomide, and dexamethasone (VTD) has shown excellent results as induction treatment in patients with multiple myeloma. However, "real-life" data in unselected Caucasian patients are lacking.

Methods: We retrospectively analyzed 41 patients treated with VTD between 2005 and 2014.

Results: Post induction, the overall response rate was $78 \%$, with $\geq$ very good partial response ( $\geq$ VGPR) in $54 \%$ and near complete/complete responses (nCR/CR) in $17 \%$ of the patients respectively. For patients proceeding to autologous stem cell transplantation (ASCT), post-transplant rates were $96 \% \geq \mathrm{VGPR}$ and $48 \% \mathrm{nCR} / \mathrm{CR}$. Median progression free survival (PFS) was 24 months and the estimated 1-year and 2-year overall survival (OS) rates were $95 \%$ and $76 \%$, respectively. Subgroup analyses revealed significantly longer OS and PFS in patients with a $\geq$ VGPR as first response status compared to those with a <VGPR [OS 44 vs. 25 months ( $p=0.036$ ); PFS 29.5 vs. 16 months $(p=0.011)$ ], as well as in patients who underwent ASCT compared to not transplanted patients [OS 41 vs. 23.5 months ( $p=0.002)$; PFS 28 vs. 23 months $(p=0.003)$ ]. In 6 patients $(15 \%)$ therapy was switched to another regimen due to lack of response $(<P R, n=4)$, cardiac decompensation $(n=1)$ or prolonged neutropenia ( $n=1)$. Nonhematological grade III/IV toxicities were peripheral neuropathy $(2 \%)$, infections $(7 \%)$, herpes zoster $(5 \%)$, and thromboembolic events (2\%). Dose reductions of thalidomide and/or bortezomib were necessary in $24 \%$ of the patients because of peripheral neuropathy.
\end{abstract}

Conclusion: The VTD regimen was found to be a highly effective and well tolerated induction regimen for multiple myeloma patients outside clinical trials.

Keywords: VTD; ASCT; Multiple myeloma; Induction therapy; Toxicity

\section{Introduction}

The implementation of novel drugs, such as bortezomib, thalidomide, and lenalidomide into induction regimens before highdose melphalan treatment (HDT) and autologous hematopoietic stem cell transplantation (ASCT) has improved the survival of patients with multiple myeloma (MM) [1,2]. The three drug combination of bortezomib, thalidomide and dexamethasone (VTD) has shown particularly high response rates, as well as the potential to even achieve deep molecular remissions, and does not impair the mobilization and collection of hematopoietic stem cells $[3,4]$. The aim of this retrospective single center study was to evaluate the efficacy and toxicity of VTD as an induction therapy for MM outside a clinical trial in Caucasian patients.

\section{Patients and Methods}

Between October 2005 and June 2014, 41 adult patients aged between 35 and 77 years, identified by a search in the local database fraction of the Austrian Myeloma Registry, with symptomatic MM requiring treatment according to the International Myeloma Working
Group (IMWG) criteria [5], received induction therapy with VTD, consisting of bortezomib $1.3 \mathrm{mg} / \mathrm{m}^{2}$ intravenously on days $1,4,8$, and 11 , oral dexamethasone $40 \mathrm{mg}$ on days $1,2,4,5,8,9,11$ and 12 , and oral thalidomide $100 \mathrm{mg}$ daily in the evening.

All patients received low-molecular weight heparin and oral antiviral prophylaxis. After three to four cycles of VTD, peripheral blood progenitor cells (PBPC) were harvested after priming with GCSF $2 \times 10 \mu \mathrm{g} / \mathrm{kg}$ over five days in patients scheduled for high-dose therapy (mean of collected stem cells $7.22 \times 10^{6} / \mathrm{kg}$ bodyweight) without additional chemotherapy. Thalidomide was omitted in the last cycle before PBPC mobilization to optimize stem cell yield [6]. For these patients consolidation treatment consisted of $200 \mathrm{mg} / \mathrm{m}^{2}$ melphalan followed by reinfusion of PBPC. Routinely, no further antimyeloma treatment was given. Transplant ineligible patients received VTD if a rapid response was required, e.g. due to renal insufficiency.

Sampling and evaluation of patients' data was approved by the local institutional ethics committee (vote number: UN3252) in accordance with the principles of the Declaration of Helsinki.

The first response assessment was performed after three cycles of VTD according to International Uniform Response Criteria for MM [7] with the additional response category of $\mathrm{nCR}$, defined as complete disappearance of monoclonal protein on electrophoresis but positive 
Citation: Steiner N, Riehl S, Nachbaur D, Willenbacher W, Gastl G, et al. (2015) Induction Therapy with Bortezomib, Thalidomide and Dexamethasone (VTD) in Caucasian Patients with Multiple Myeloma: A Single Center Experience. J Blood Disord Transfus 6: 296. doi: $10.4172 / 2155-9864.1000296$

Page 2 of 5

immunofixation [8]. Toxicities were graded according to the "Common Terminology Criteria of Adverse Events" (CTCAE v4.03) [9].

Patients were allocated to high-risk or standard-risk groups according to IMWG criteria [10]. High-risk cytogenetics were defined as $\mathrm{t}(4 ; 14), \mathrm{t}(14 ; 16)$ and/or del17p, all by fluorescence in-situ hybridization (FISH) analysis of myeloma cells.

Statistical evaluation was performed using GraphPad PrismTM software for Windows. All tests of statistical significance were twosided. Unpaired t-test and survival analysis (Log rank-test) were used to identify differences between two groups.

\section{Results}

\section{Patient characteristics}

41 patients were treated with VTD. Table 1 summarizes the relevant clinical data and disease characteristics. Data on cytogenetic aberrations, detected by FISH on bone marrow plasma cells, were available and informative in $71 \%$; 9 patients $(22 \%)$ had high-risk cytogenetics with $\mathrm{t}(4 ; 14), \mathrm{t}(14 ; 16)$ and/or del17p.

\begin{tabular}{|c|c|c|c|}
\hline & & $N=41$ & $\%$ \\
\hline \multirow[t]{2}{*}{ Age at diagnosis } & Median age & 58 & \\
\hline & Range & $35-77$ & \\
\hline \multirow[t]{2}{*}{ Sex } & Male & 29 & 71 \\
\hline & Female & 12 & 29 \\
\hline \multirow[t]{3}{*}{ ISS } & 1 & 16 & 39 \\
\hline & II & 12 & 29 \\
\hline & III & 13 & 32 \\
\hline \multirow[t]{4}{*}{ Immunoglobulin isotype } & $\lg G$ & 24 & 59 \\
\hline & $\lg \mathrm{A}$ & 5 & 12 \\
\hline & $\lg M$ & 3 & 7 \\
\hline & LC & 9 & 22 \\
\hline \multirow[t]{3}{*}{ Karyotype } & Normal & 8 & 20 \\
\hline & Aberrant & 28 & 68 \\
\hline & Not reported & 5 & 12 \\
\hline \multirow[t]{2}{*}{ Cytogenetic risk group (by FISH) } & High risk ${ }^{*}$ & 9 & 22 \\
\hline & Standard risk & 27 & 66 \\
\hline
\end{tabular}

$\mathrm{N}$ : Number of Patients; ISS: International Staging System; LC: Light chain myeloma; FISH: Fluorescence In-Situ Hybridization. "High risk cytogenetics defined as $t(4 ; 14), t(14 ; 16)$ and/or del17p

Table 1: Clinical data and disease characteristics of the patients.

\section{High response to VTD-induction therapy and comparison before and after ASCT}

Table 2a shows the results of VTD-induction therapy. The median number of VTD-cycles applied was 3 (1-6 cycles). A $\geq$ VGPR was achieved in $54 \%(n=22)$ of the patients and $24 \%(n=10)$ reached a partial response (PR). A minor response (MR) was achieved in 1 patient. and a stable disease (SD) in 3 patients (7\%), respectively, whereas in 5 patients the disease progressed. Table $2 b$ shows the response rates of patients after VTD-induction therapy compared to the results of other VTD-trials [11-15].

In 28 patients $(68 \%)$ PBPC were collected. The mean number of collected CD $34^{+}$cells was $7.22 \times 10^{6} / \mathrm{kg}$ bodyweight (range $2.13 \times 10^{6}-$ $26 \times 10^{6} / \mathrm{kg}$ ). 25 patients received HDT and ASCT. The median of VTD-cycles before ASCT was 4.16 patients (39\%) did not proceed to ASCT due to age $(n=4 ; 10 \%)$, comorbidity $(n=5 ; 12 \%)$, mycobacterial infection $(n=1 ; 2 \%)$ or insufficient response $(<P R, n=6 ; 15 \%)$. Postinduction, $64 \%$ of the transplant eligible 25 patients reached a $\geq$ VGPR, thereof $12 \%$ a CR $(n=3)$, and $36 \%$ reached a PR $(n=9)$. Three months after ASCT the ORR was $100 \%$ with a $\geq$ VGPR in $96 \%$ of the patients $48 \% \mathrm{CR} / \mathrm{nCR}(\mathrm{n}=12), 48 \%$ VGPR $(\mathrm{n}=12)$ and $1 \mathrm{PR}$.

\begin{tabular}{|l|l|l|}
\hline & $\mathbf{N}=\mathbf{4 1}$ & $\%$ \\
\hline No. of VTD-cycles (mean) & 3 & \\
\hline ORR & 32 & 78 \\
\hline CR & 6 & 15 \\
\hline nCR & 1 & 2 \\
\hline VGPR & 15 & 37 \\
\hline PR & 10 & 24 \\
\hline MR & 1 & 2 \\
\hline Stable disease & 3 & 7 \\
\hline PD & 5 & 12 \\
\hline $\begin{array}{l}\text { ORR: Overall Response Rate (>PR); CR: Complete Response; nCR=Near } \\
\text { Complete Response; VGPR: Very Good Partial Response; PR: Partial } \\
\text { Response; MR: Minor Response; PD: Progressive Disease }\end{array}$ \\
\hline
\end{tabular}

Table 2a: Response rate after VTD-induction therapy according to the International Myeloma Working Group response criteria [7].

\begin{tabular}{|c|c|c|c|c|c|c|}
\hline References & $\begin{array}{l}\text { Patient } \\
\text { s (n) }\end{array}$ & $\begin{array}{l}\text { ORR } \\
(\%)\end{array}$ & $\begin{array}{l}\geq n C R \\
(\%)\end{array}$ & $\begin{array}{l}\text { ZVGPR } \\
(\%)\end{array}$ & PR (\%) & $\begin{array}{l}\text { MR/SD } \\
(\%)\end{array}$ \\
\hline Our patients & 41 & 78 & 17 & 54 & 24 & 10 \\
\hline Cavo et al. [11] & 236 & 93 & 31 & 62 & 31 & 7 \\
\hline Rosinol et al. [12] & 130 & 85 & 35 & 60 & 25 & 6 \\
\hline Moreau et al. [13] ${ }^{* *}$ & 100 & 88 & 31 & 49 & 39 & NR \\
\hline $\begin{array}{l}\text { Kaufman et al. } \\
{[14]^{* \star *}}\end{array}$ & 44 & 91 & 20 & 57 & 34 & 5 \\
\hline Buda et al. [15] & 43 & 91 & 30 & 51 & 40 & 7 \\
\hline
\end{tabular}

ORR: Overall Response Rate $(\geq P R)$; $C R=$ Complete Response; $n C R=N e a r$ Complete Response; VGPR: Very Good Partial Response; PR: Partial Response; MR: Minor Response; SD: Stable Disease; NR=Not Reported. *6 cycles VTD, ${ }^{* *} 4$ cycles VTD, ${ }^{* * *}$ median duration of VTD-induction: 4 cycles (range $2-8$ cycles).

Table 2b: Response rate after VTD-induction therapy compared with the results of other VTD-trials. 
Citation: Steiner N, Riehl S, Nachbaur D, Willenbacher W, Gastl G, et al. (2015) Induction Therapy with Bortezomib, Thalidomide and Dexamethasone (VTD) in Caucasian Patients with Multiple Myeloma: A Single Center Experience. J Blood Disord Transfus 6: 296. doi: $10.4172 / 2155-9864.1000296$

Page 3 of 5

35 patients were evaluable for OS and PFS. 6 patients $(15 \%)$ discontinued VTD-induction due to lack of response $(<\mathrm{PR}, \mathrm{n}=4)$, cardiac decompensation $(\mathrm{n}=1)$ or prolonged neutropenia $(\mathrm{n}=1)$. At data cut-off (May 31, 2014), the median follow-up was 32 months (range 7-88). The median PFS was 24 months. The median OS has not been reached, the estimated 1-year and 2-year OS rates were $95 \%$ and $76 \%$, respectively. An analysis of PFS and OS according to the first response status revealed significant differences between patients with a $\geq \operatorname{VGPR}(\mathrm{n}=20 ; 57 \%)$ and patients with $<\operatorname{VGPR}(\mathrm{n}=15 ; 43 \%)$ [OS 44 vs. 25 months $(\mathrm{p}=0.036)$; PFS 29.5 vs. 16 months $(\mathrm{p}=0.011)$ ]. Significant differences in OS and PFS were also evident in patients who underwent ASCT $(\mathrm{n}=25 ; 71 \%)$ and patients who did not undergo ASCT ( $n=10 ; 29 \%$ ) [OS 41 vs. 23.5 months ( $\mathrm{p}=0.002$ ); PFS 28 vs. 23 months $(\mathrm{p}=0.003)]$. Overall, there was no significant difference regarding OS and PFS between cytogenetic high-risk $(n=7 ; 20 \%)$ and standard-risk patients $(\mathrm{n}=24 ; 69 \%)$. Median OS was 29 months in the high-risk group vs. 40 month in the standard-risk group $(\mathrm{p}=0.27)$, median PFS was 21 months (high-risk) vs. 28 months (standard-risk; $\mathrm{p}=0.17$ ). Results are shown in Figure 1A-C.

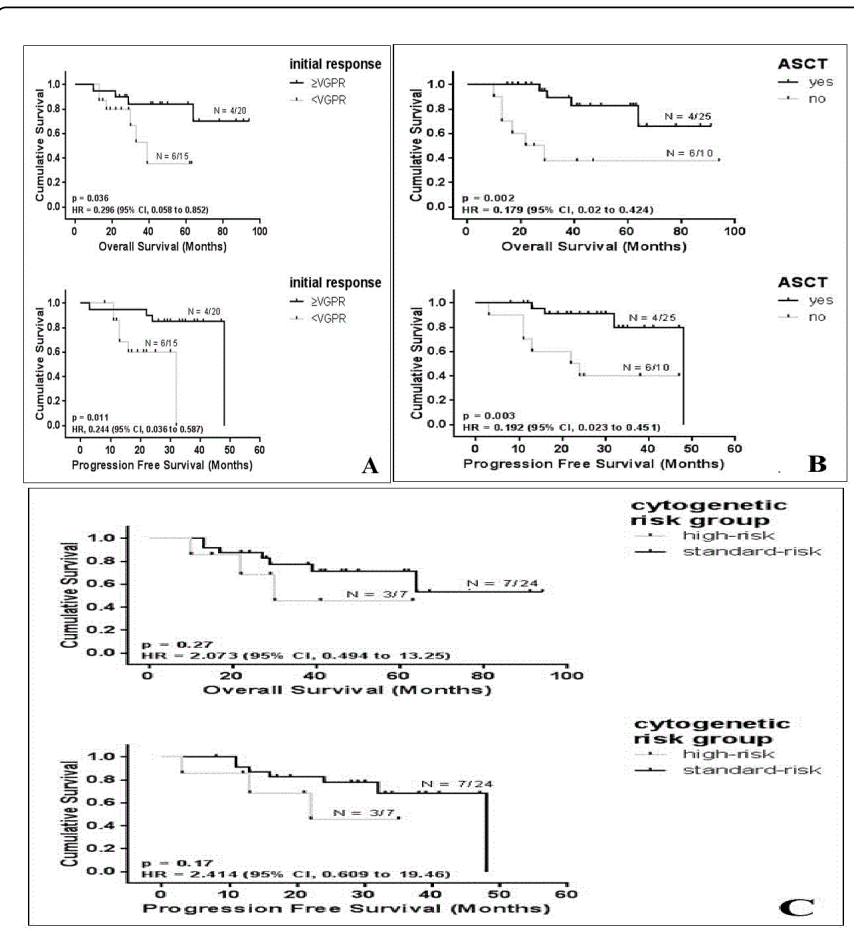

Figure 1: Survival - results of subgroups of patients (patients). A) Comparison of OS and PFS between patients with a $\geq$ VGPR and patients with a $<\mathrm{VGPR} ; 35$ patients. Both OS and PFS were significantly longer in patients with $a \geq \operatorname{VGPR}$ ( $\mathrm{p}$ values $<0.05$ ). $\mathrm{B}$ ) Comparison of OS and PFS between patients who underwent ASCT (ASCT yes) or not (ASCT no); 35 patients. Both OS and PFS were significantly longer in patients who underwent ASCT ( $p$ values $<0.05$ ). C) Comparison of OS and PFS based on cytogenetic risk groups (high-risk vs. standard-risk); 31 patients $P$ values $<0.05$ indicate statistical significance (log rank). OS and PFS are time-toevents data. $\mathrm{N}=$ number of events/number of patients $\mathrm{HR}=\mathrm{Hazard}$ ratio.

\section{Toxicities and adverse events associated with therapy}

Toxicities are shown in Table 3a. Peripheral neuropathy (PN) was the most common adverse event. Severe infections as defined by CTCAE v4.03 occurred in 3 patients (Mycobacterial infection $n=1$, febrile neutropenia $n=2$ ). Two patients developed a herpes zoster reactivation despite adequate prophylaxis. Hematological toxicities grade III/IV were thrombocytopenia $(n=3)$ and neutropenia $(n=2) .2$ patients had a thromboembolic event, of which one were grade III/IV (catheter-associated thrombosis of the vena subclavian $n=1$, ischemic stroke $\mathrm{n}=1$ ). Table $3 \mathrm{~b}$ shows the side effects of the patients compared to the results of other VTD-trials [11-14].

Dose reductions of thalidomide and/or bortezomib were necessary in 10 patients $(24 \%)$ because of $\mathrm{PN}$.

\begin{tabular}{|l|l|l|l|l|}
\hline & \multicolumn{2}{l|}{ All grades } & \multicolumn{2}{l|}{ Grade III/IV } \\
\cline { 2 - 5 } & $\mathbf{N}=\mathbf{4 1}$ & $\mathbf{\%}$ & $\mathbf{N}=\mathbf{4 1}$ & $\%$ \\
\hline Herpes zoster & 2 & 5 & 2 & 5 \\
\hline Infections (bacterial) & 8 & 20 & 3 & 7 \\
\hline Peripheral neuropathy & 18 & 44 & 1 & 2 \\
\hline Neutropenia & 8 & 20 & 2 & 5 \\
\hline Thrombocytopenia & 6 & 15 & 3 & 7 \\
\hline Thromboembolic events & 2 & 5 & 1 & 2 \\
\hline Nausea & 1 & 2 & 0 & 0 \\
\hline
\end{tabular}

Table 3a: Adverse events associated with VTD therapy.

\begin{tabular}{|l|l|l|l|l|l|}
\hline References & $\begin{array}{l}\text { Infection } \\
\mathbf{s}(\%)\end{array}$ & $\begin{array}{l}\text { Peripheral } \\
\text { neuropath } \\
\mathbf{y}(\%)\end{array}$ & $\begin{array}{l}\text { Neutropeni } \\
\text { a (\%) }\end{array}$ & $\begin{array}{l}\text { Thrombo } \\
- \\
\text { cytopeni } \\
\text { a (\%) }\end{array}$ & $\begin{array}{l}\text { Thrombo } \\
\text {-embolic } \\
\text { events } \\
\text { (\%) }\end{array}$ \\
\hline Our patients & 7 & 2 & 5 & 7 & 2 \\
\hline $\begin{array}{l}\text { Cavo et al. } \\
{[11]}\end{array}$ & 3 & 10 & NR & NR & 3 \\
\hline $\begin{array}{l}\text { Rosinol et al. } \\
{[12]}\end{array}$ & 21 & 14 & 10 & 8 & 12 \\
\hline $\begin{array}{l}\text { Moreau et al. } \\
{[13]}\end{array}$ & 10 & 3 & 0 & 3 & 2 \\
\hline $\begin{array}{l}\text { Kaufman et al. } \\
{[14]}\end{array}$ & 0 & 9 & 0 & 2 & 4 \\
\hline NR: Not Reported. & & & & \\
\hline
\end{tabular}

Table 3b: Grade III/IV toxicities associated with VTD-induction therapy - Comparison to the results of other VTD-trials.

\section{Discussion}

Various combinations of doublet, triplet and quadruplet regimes including proteasome inhibitors, antracyclines, corticosteroids, immune-modulatory drugs and alkylators, have been used for the initial therapy of patients with MM before ASCT. Still, the optimal choice of a regimen for initial therapy is yet not clear, but regimens combining the most active class of drugs (proteasome inhibitors and 
Citation: Steiner N, Riehl S, Nachbaur D, Willenbacher W, Gastl G, et al. (2015) Induction Therapy with Bortezomib, Thalidomide and Dexamethasone (VTD) in Caucasian Patients with Multiple Myeloma: A Single Center Experience. J Blood Disord Transfus 6: 296. doi: $10.4172 / 2155-9864.1000296$

Page 4 of 5

immunomodulatory drugs) seem to be most logical therapeutic backbones.

The aim of this retrospective study was to evaluate the response, side effects, and the outcome of patients with MM using the VTDprotocol as induction therapy in unselected Caucasian patients outside a clinical trial, thereby reflecting "real life" myeloma treatment. Comparing our results to published data from clinical trials and retrospective studies in which VTD was given as induction regimen [11-15] (Table 2b), our data confirm that the VTD protocol is a very effective induction regimen outside clinical trials. The observed ORR in our cohort was $78 \%$, with $17 \%$ of the patients reaching a $\mathrm{CR} / \mathrm{nCR}$, and $37 \%$ of the patients reaching VGPR ( $54 \% \geq$ VGPR). These are impressive results in an unselected patient cohort, due to excellent disease control in a short period of time, which is in accordance with published data on VTD-induction therapy [14].

For patients proceeding to ASCT, $12 \%$ of the patients reached a CR and $64 \%$ a $\geq$ VGPR. After ASCT, all but one patient (96\%) reached $\geq \mathrm{VGPR}$, thereof $48 \%$ a $\mathrm{CR} / \mathrm{nCR}$. Optimal response is considered a prerequisite for long-term disease control [16]. Our post-transplant results are similar to that of the large, randomized phase 3 GIMEMA trial, which compared VTD and TD as a pre-transplant induction therapy followed by double ASCT and further consolidation in patients with newly diagnosed MM [11]. In this trial, $31 \%$ of the patients who received induction therapy with VTD reached a $\mathrm{CR} / \mathrm{nCR}$, and $62 \%$ achieved $\geq \mathrm{VGPR}$. After ASCT-consolidation, rates of $\mathrm{CR} / \mathrm{nCR}$ and $\geq \mathrm{VGPR}$ were $52 \%$ and $79 \%$, respectively. As the GIMEMA trial used further post-transplantation VTD consolidation only long-term results will proof the potential additional benefit of this therapeutic element. Furthermore, Ladetto [17] and co-workers reported persistent molecular remission with this approach arguing for minimal residual disease (MRD) triggered allocation of therapies in future clinical trials. Comparing VTD with TD and VBMCP/ VBAD/B, also the PETHEMA/GEM study showed similar results in the VTD arm as we observed in our patients after ASCT [12]. The rate of CR increased from $35 \%$ after VTD-induction therapy to $46 \%$ after ASCT. Of note, our study represents data of an unselected patient cohort.

In our patients the median PFS was 24 months. The median OS from initiation of VTD induction had not been reached after a median follow-up of 32 months, and the estimated 1-year and 2-year OS rates were $95 \%$ and $76 \%$, respectively. These data are comparable to the retrospective data of Kaufman et al. (median follow-up 25 months; PFS 27.5 months; 1-year OS rate 95\%, 2-year OS rate 82\%) [14]. Several studies suggest that the quality of response after induction therapy is a predictor for survival time [18-21]. Consistently, our data show significant differences in OS and PFS between patients with initial response $\geq$ VGPR and $<$ VGPR (figure $1 b$ ).

In general, the VTD-regime is well tolerated [11]. The most common non-hematological toxicity we observed was PN in $44 \%$ of the patients (all grades $n=18$, grade III $n=1$ ), which is in accordance to published toxicity data. However, only one patient (2\%) developed a PN grade III and no grade IV PN was observed. In the GIMEMA trial $10 \%$ of the patients had PN grade III/IV [11]. Kaufman et al. reported similar results regarding the overall incidence of $\mathrm{PN}$ as we observed (55\%) [14]. In table 3a, additional grade III/IV toxicities associated with VTD-induction therapy are shown. A dose reduction was necessary in $24 \%$ of the patients due to development of PN. The Intergroupe Francophone du Myelome (IFM) conducted a phase 3 trial comparing a reduced dose of bortezomib $\left(1 \mathrm{mg} / \mathrm{m}^{2}\right.$ i.v. on days 1 ,
4,8 and 11 of a 3 week cycle) and thalidomide (100 mg/day) plus dexamethasone (vtD) with the standard VD-regimen [13]. They could show that in spite of adding thalidomide to the vD-group, there were less cases of PN noticed as in the VD-regime group [13]. Another strategy to improve tolerability of bortezomib was published first in the MMY-3021 Phase III trial [22], where subcutaneous administration of bortezomib in patients with relapsed MM showed a non-inferior efficacy (ORR after induction in both groups 42\%) and low rates of $\mathrm{PN}$ compared to the intravenous administration of bortezomib (PN all grades: s.c. $38 \%$ vs i.v. $53 \%$ ). These results are confirmed by a number of other prospective and retrospective studies with subcutaneous bortezomib in diverse settings (Cavallo et al. [23]).

In summary, our data confirm VTD as an effective and well tolerated induction therapy in unselected Caucasian patients with MM outside clinical trials. Both tolerance (bortezomib s.c.) as well as applicability of the regimen in elderly patients (bortezomib s.c./ weekly) might be further optimized to achieve even better treatment results in more myeloma patients.

\section{Acknowledgements}

This work was supported by an educational grant from Janssen Austria for data analysis and the diploma thesis of Stephanie Riehl. Patients were identified by Mag. Roman Weger from the Austrian Myeloma Registry. Author's contributions to this work: Steiner and Riehl performed the data analysis \& interpretation. Gunsilius, Gastl, Nachbaur, Willenbacher and Steiner wrote the paper.

\section{Conflict of Interest}

The authors declare no financial conflict of interest.

\section{References}

1. Attal M, Harousseau JL, Stoppa AM, Sotto JJ, Fuzibet JG, et al. (1996) A prospective, randomized trial of autologous bone marrow transplantation and chemotherapy in multiple myeloma. Intergroupe Français du Myélome. N Engl J Med 335: 91-97.

2. Child JA, Morgan GJ, Davies FE, Owen RG, Bell SE, et al. (2003) Highdose chemotherapy with hematopoietic stem-cell rescue for multiple myeloma. N Engl J Med 348: 1875-1883.

3. Barlogie B, Anaissie E, van Rhee F, Haessler J, Hollmig K, et al. (2007) Incorporating bortezomib into upfront treatment for multiple myeloma: early results of total therapy 3. Br J Haematol 138: 176-185.

4. Pineda-Roman M, Zangari M, van Rhee F, Anaissie E, Szymonifka J, et al. (2008) VTD combination therapy with bortezomib-thalidomidedexamethasone is highly effective in advanced and refractory multiple myeloma. Leukemia 22: 1419-1427.

5. International Myeloma Working Group (2003) Criteria for the classification of monoclonal gammopathies, multiple myeloma and related disorders: a report of the International Myeloma Working Group. Br J Haematol 121: 749-757.

6. Auner HW, Mazzarella L, Cook L, Szydlo R, Saltarelli F, et al. (2011) High rate of stem cell mobilization failure after thalidomide and oral cyclophosphamide induction therapy for multiple myeloma. Bone Marrow Transplant 46: 364-367.

7. Durie BG, Harousseau JL, Miguel JS, Bladé J, Barlogie B, et al. (2006) International uniform response criteria for multiple myeloma. Leukemia 20: 1467-1473.

8. Richardson PG, Barlogie B, Berenson J, Singhal S, Jagannath S, et al. (2003) A phase 2 study of bortezomib in relapsed, refractory myeloma. N Engl J Med 348: 2609-2617. 
Citation: Steiner N, Riehl S, Nachbaur D, Willenbacher W, Gastl G, et al. (2015) Induction Therapy with Bortezomib, Thalidomide and Dexamethasone (VTD) in Caucasian Patients with Multiple Myeloma: A Single Center Experience. J Blood Disord Transfus 6: 296. doi: $10.4172 / 2155-9864.1000296$

Page 5 of 5

9. http://evs.nci.nih.gov/ftp1/CTCAE/ CTCAE_4.03_2010-06-14_QuickReference_5x7.pdf.

10. Fonseca R, Bergsagel PL, Drach J, Shaughnessy J, Gutierrez N, et al. (2009) International Myeloma Working Group molecular classification of multiple myeloma: spotlight review. Leukemia 23: 2210-2221.

11. Cavo M, Tacchetti P, Patriarca F, Petrucci MT, Pantani L, et al. (2010) Bortezomib with thalidomide plus dexamethasone compared with thalidomide plus dexamethasone as induction therapy before, and consolidation therapy after, double autologous stem-cell transplantation in newly diagnosed multiple myeloma: a randomised phase 3 study. Lancet 376: 2075-2085.

12. Rosiñol L, Oriol A, Teruel AI, Hernández D, López-Jiménez J, et al. (2012) Superiority of bortezomib, thalidomide, and dexamethasone (VTD) as induction pretransplantation therapy in multiple myeloma: a randomized phase 3 PETHEMA/GEM study. Blood 120: 1589-1596.

13. Moreau P, Avet-Loiseau H, Facon T, Attal M, Tiab M, et al. (2011) Bortezomib plus dexamethasone versus reduced-dose bortezomib, thalidomide plus dexamethasone as induction treatment before autologous stem cell transplantation in newly diagnosed multiple myeloma. Blood 118: 5752-5758.

14. Kaufman JL, Nooka A, Vrana M, Gleason C, Heffner LT, et al. (2010) Bortezomib, thalidomide, and dexamethasone as induction therapy for patients with symptomatic multiple myeloma: a retrospective study. Cancer 116: 3143-3151.

15. Buda G, Orciuolo E, Carulli G, Galimberti S, Ghio F, et al. (2013) Bortezomib with thalidomide plus dexamethasone compared with thalidomide plus doxorubicin and dexamethasone as induction therapy in previously untreated multiple myeloma patients. Acta Haematol 129: 35-39.
16. Ludwig H, Beksac M, Bladé J, Boccadoro M, Cavenagh J, et al. (2010) Current multiple myeloma treatment strategies with novel agents: a European perspective. Oncologist 15: 6-25.

17. Ladetto M, Pagliano G, Ferrero S, Cavallo F, Drandi D, et al. (2010) Major tumor shrinking and persistent molecular remissions after consolidation with bortezomib, thalidomide, and dexamethasone in patients with autografted myeloma. J Clin Oncol 28: 2077-2084.

18. Cavo M (2006) Proteasome inhibitor bortezomib for the treatment of multiple myeloma. Leukemia 20: 1341-1352.

19. van de Velde HJ, Liu X, Chen G, Cakana A, Deraedt W, et al. (2007) Complete response correlates with long-term survival and progressionfree survival in high-dose therapy in multiple myeloma. Haematologica 92: 1399-1406.

20. Harousseau JL, Palumbo A, Richardson PG, Schlag R, Dimopoulos MA, et al. (2010) Superior outcomes associated with complete response in newly diagnosed multiple myeloma patients treated with nonintensive therapy: analysis of the phase 3 VISTA study of bortezomib plus melphalan-prednisone versus melphalan-prednisone. Blood 116: 3743-3750.

21. Harousseau JL, Attal M, Avet-Loiseau H (2009) The role of complete response in multiple myeloma. Blood 114: 3139-3146.

22. Moreau P, Pylypenko H, Grosicki S, Karamanesht I, Leleu X, et al. (2011) Subcutaneous versus intravenous administration of bortezomib in patients with relapsed multiple myeloma: a randomised, phase 3, noninferiority study. Lancet Oncol 12: 431-440.

23. Lamm W, Drach-Schauer B, Eder S, Drach J (2013) Bortezomib administered subcutaneously is well tolerated in bortezomib-based combination regimens used in patients with multiple myeloma. Oncology 85: 223-227. 